\title{
THE EFFECT OF HYPOTHERMIA ON THE RESPIRATORY RESPONSE TO CARBON DIOXIDE
}

\author{
Gerald Edelist, M.D. *
}

ReCENTLY Regan and Eger ${ }^{1}$ and earlier Salzano and Hall ${ }^{2}$ indicated that moderate hypothermia is a marked respiratory depressant, as evidenced by a decrease in the slope of the $\mathrm{CO}_{2}$ response-ventilation line. Cranston and his group, ${ }^{3}$ however, reported no change in respiratory response to carbon dioxide. We had noticed low $\mathrm{Pa}_{\mathrm{CO}_{2}}$ levels in the postoperative period in patients undergoing hypothermia during surgery for cerebral aneurysms. This finding led us to the present study. The method is remarkably similar to that used by Regan and Eger, ${ }^{1}$ although the design was independently conceived. The results, however, are different and therefore it is necessary to report our findings.

\section{METHOD}

Five dogs were anaesthetized with halothane, nitrous oxide, and oxygen from a Foregger anaesthesia machine using a tight-fitting animal mask; no intravenous agents were given for induction. Following induction, nitrous oxide was discontinued, an endotracheal tube was inserted, and the animal was allowed to breathe spontaneously a halothane-oxygen mixture. A polyethylene catheter was inserted into a femoral artery for the recording of arterial blood pressure and the sampling of blood gases. Arterial pressure was recorded with a Statham P 23AA pressure transducer coupled to an Offner type R dynograph. Five per cent dextrose in water was infused through a polyethylene catheter inserted into a femoral vein.

The end-tidal halothane concentration was monitored by a Beckman infrared halothane analyser and periodically checked by gas chromatography. The minin:um alveolar anaesthetic concentration of halothane (MAC) consistent with lack of movement in response to clamping of the dogs' tails was determined using the method described by Eger and Merkel. ${ }^{4}$ End-tidal $\mathrm{P}_{\mathrm{CO}_{2}}$ was monitored with a Beckman LB- 1 infrared $\mathrm{CO}_{2}$ analyser.

When the animals' end-tidal halothane concentration and end-tidal $\mathrm{P}_{\mathrm{CO}_{2}}$ had remained constant over at least a fifteen minute period during normothermia or a thirty minute period during hypothermia, a resting minute ventilation (VE) was determined by means of a Wright ventilation meter inserted between the endotracheal tube and exhalation side of the $\mathrm{x}$-piece of the circle system. Simultaneously, arterial blood was drawn and analysed for $\mathrm{Pa}_{\mathrm{CO}_{2}}, \mathrm{~Pa}_{\mathrm{O}_{2}}$, and $\mathrm{pH}$, using respectively Severinghaus, Clarke, and Radiometer electrodes coupled to a Beckman 160 physiologic gas analyser. Carbon dioxide was then added to the inspired mixture, bypassing the $\mathrm{CO}_{2}$ absorber from a $\mathrm{CO}_{2}$ tank to maintain an increased

-Department of Anaesthesia, University of Toronto and New Mount Sinai Hospital, Toronto. 


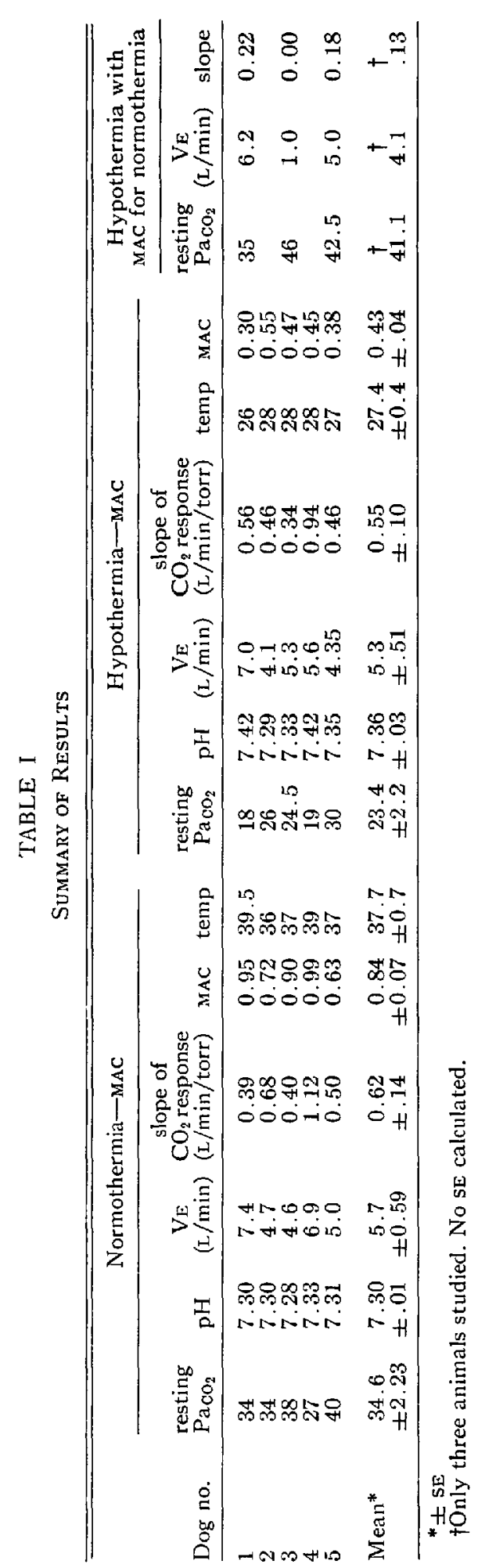


end-tidal carbon dioxide tension. This end-tidal $\mathrm{PcO}_{2}$ was held constant for ten minutes with $\mathrm{VE}$ and $\mathrm{PaCO}_{2}$ being determined at the end of the ten minute period. Four points at different $\mathrm{Pa}_{\mathrm{CO}_{2}}$ levels were determined in this way, and a $\mathrm{CO}_{2}$ response-ventilation curve was constructed. The animal was then cooled approximately $10^{\circ} \mathrm{C}$ by surface application of ice. Temperature was measured by a mercury thermometer inserted high into the rectum. MAC was redetermined at this new temperature. The response to normal and increased concentration of carbon dioxide was then measured. Blood gas values were corrected for temperature using the Severinghaus Blood Gas Calculator. ${ }^{5}$

Additionally, in three hypothermic dogs, the concentration of halothane was increased to approximately the alveolar concentration required to prevent movement in response to tail clamp at normothermia, and the $\mathrm{CO}_{2}$ ventilatory response measurements were repeated.

\section{Results}

A summary of the results is presented in Table I. There was a decrease in MAC of 49 per cent with a $10^{\circ} \mathrm{C}$ fall in temperature from $0.84 \pm .07$ to $0.43 \pm .04$, which is highly significant $(p<0.001)$. The resting ventilation did not change significantly with the decreased temperature (from $5.7 \pm 0.59 \mathrm{~L} / \mathrm{min}$ to $5.3 \pm 0.5$ $\mathrm{L} / \mathrm{min}, p=0.6$ ). However, the resting $\mathrm{Pa}_{\mathrm{CO}_{2}}$ was significantly lower, from $34.6 \pm$ 2.23 torr to $23.4 \pm 2.2$ torr, $p<0.01$ ). If the $\mathrm{CO}_{2}$ ventilation-response curves representing the mean of five dogs (Fig. 1) are extrapolated back to the $5 \mathrm{~L} / \mathrm{min}$ ventilation point, the $\mathrm{Pa}_{\mathrm{CO}_{2}}$ for the normothermic dogs is 33 torr, while for the dogs in hypothermia it is 23 torr. At the $10 \mathrm{~L} / \mathrm{min}$ ventilation point the $\mathrm{Pa}_{\mathrm{CO}_{2}}$ values are 41.5 torr during normothermia and 32 torr during hypothermia. The apnoeic threshold was not actually measured, but by extrapolating the $\mathrm{CO}_{2}$ response curves in Figure 1 back to their intercept with the abcissa, the $\mathrm{Pa}_{\mathrm{CO}_{2}}$ at zero ventilation during normothermia is 25 torr while for hypothermia it is 14 torr. Thus there is a considerable shift to the left of the $\mathrm{CO}_{2}$ response curve during hypothermia. This shift to the left was exhibited by each of the dogs studied. The mean slope of the $\mathrm{CO}_{2}$ response curves (Fig. 1) was not significantly decreased (from $0.62 \pm .14 \mathrm{~L} / \mathrm{min} /$ torr to $0.55 \mathrm{~L} / \mathrm{min} /$ torr $\pm 0.10, p=0.6$ ). The changes in slope for the five animals studied were inconsistent (Table I).

Thus at equipotent anaesthetic doses the effect of hypothermia is to shift the $\mathrm{CO}_{2}$ response curve to the left without significantly changing the slope. In the three animals which were cooled while the anaesthetic concentration was maintained at normothermic $\mathrm{MAC}$, the mean resting $\mathrm{Pa}_{\mathrm{CO}_{2}}$ was 41.1 torr, while the slope was profoundly depressed to $0.13 \mathrm{~L} / \mathrm{min} /$ torr. This depression of ventilation is due to deepening of the anaesthesia rather than to any effect of the hypothermia itself.

\section{DisCUSSION}

Analysis of the respiratory response to hypothermia during anaesthesia has been hindered by one major problem: the depth of anaesthesia varies inversely as the temperature changes, if the concentration is held constant. ${ }^{7}$ The profound effect of anaesthetic depth on respiration, well known to all anaesthetists, made 


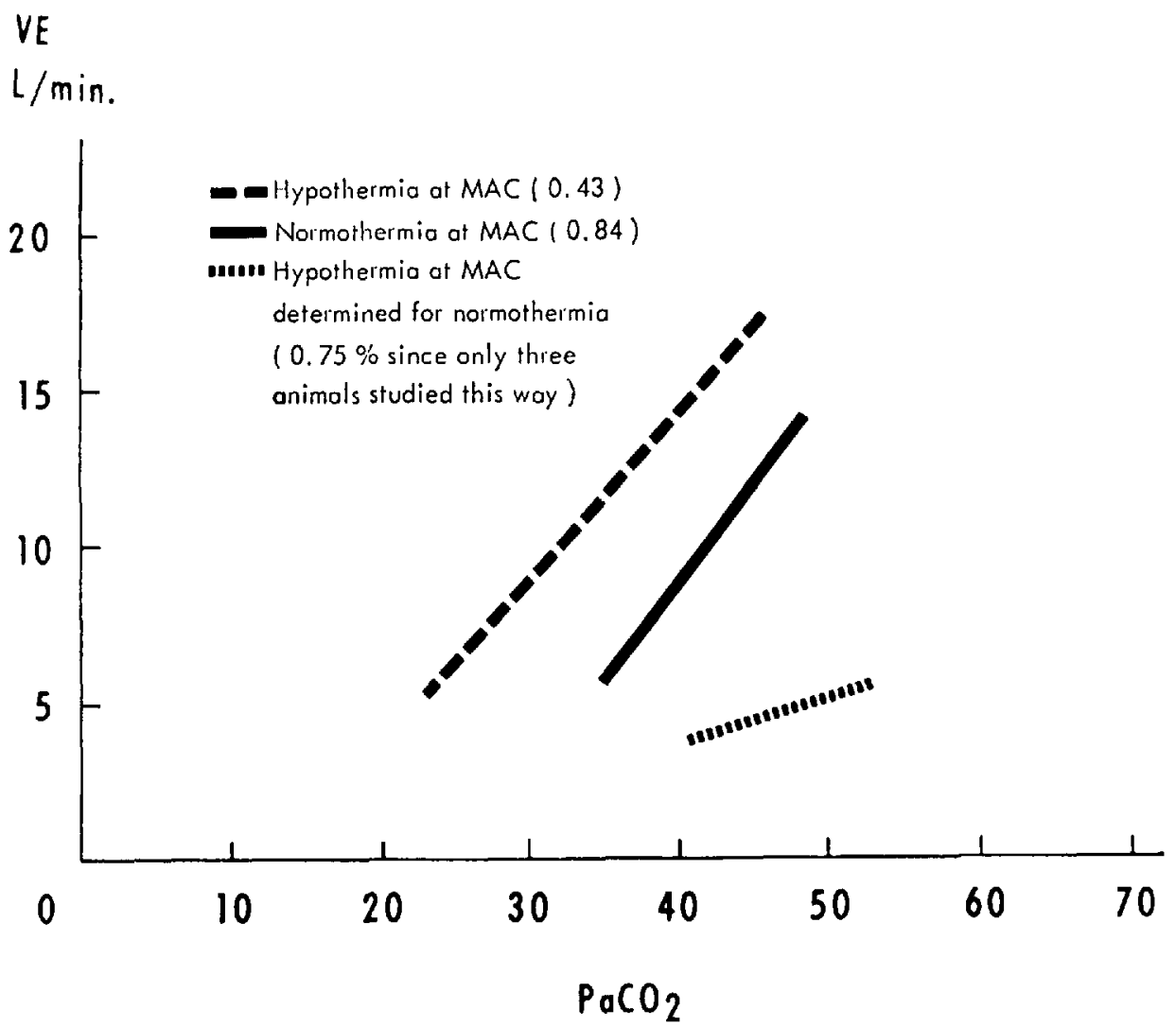

Figure 1. Mean $\mathrm{CO}_{2}$ response curves of all animals studied.

it virtually impossible to determine whether temperature change or anaesthetic agent caused the noted change in respiration. This problem has been circumvented by the concept of MAC. ${ }^{4}$ The importance of anaesthetic depth in the study of respiratory responses during hypothermia is amply demonstrated by comparing the response to carbon dioxide at $27^{\circ} \mathrm{C}$ when the depth of anaesthesia has been maintained at MAC I $(0.43 \pm .08)$ with the response when the depth is allowed to increase ( 0.75 per cent). There is a marked depression of the slope of the $\mathrm{CO}_{2}$ response-ventilation line at 0.75 per cent. By maintaining the animal at MAC for a given temperature the profound depression of the slope of the $\mathrm{CO}_{2}$ response curve disappears and the position of the curve is shifted far to the left.

The previous literature on the effect of hypothermia on respiratory response to $\mathrm{CO}_{2}$, adequately summarized in the paper of Regan and Eger, has been contradictory, some claiming depressant actions of hypothermia on respiration, others no depression. We interpret our results as meaning that the threshold of the respiratory centre is lowered, while the gain or sensitivity of the centre is unchanged. Thus in our animals the $\mathrm{Pa}_{\mathrm{CO}_{2}}$ is lower during hypothermia than at normothermia for any level of ventilation below $10 \mathrm{~L}$. Regan, ${ }^{1}$ who also maintained anaesthesia constant, on the other hand reported a marked depression of 
the slope of the mean $\mathrm{CO}_{2}$ response curve of all his animals with the resting $\mathrm{Pa}_{\mathrm{CO}_{2}}$ and ventilation both lower during hypothermia than during normothermia.

We used techniques similar to those of Regan, although several differences existed. We examined $\mathrm{CO}_{2}$ response at $\mathrm{MAC}$, while he examined it at end-tidal halothane concentration of 1 per cent, representing slightly deeper anaesthesia. Also, we actually determined MAC in each animal, while he assumed equipotency at normo- and hypothermia from data produced in other animals in his laboratory. In addition, our animals had metabolic acidosis during both normothermia and hypothermia, with the acidosis increasing during the period of hypothermia. These factors would tend to increase the slope of the $\mathrm{CO}_{2}$ response curves in our animals relative to Regan's. However, the large differences could not be explained on this basis alone.

The mechanism by which the threshold of the respiratory centre is lowered by hypothermia remains obscure. In general, any increased afferent input into the respiratory centre from the periphery will shift the carbon dioxide response curve to the left. ${ }^{6}$ It is possible that stimulation of the skin by cold may shift the curve or that some other effect of hypothermia from the periphery is operating. In addition, there is some evidence that at $27^{\circ} \mathrm{C}$ there is hyperactivity of the reticular activating system. ${ }^{8}$ Any increase in the input to the respiratory centre from the reticular activating system would tend to shift the $\mathrm{CO}_{2}$ response curve to the left.

Severinghaus proposed that normal ventilation during hypothermia is that in which carbon dioxide elimination equals its rate of metabolic production as cooling progresses. ${ }^{9}$ This means that the blood carbon dioxide content in the absence of metabolic acidosis remains unchanged, with the $\mathrm{pH}_{\mathrm{a}}$ and $\mathrm{Pa}_{2}$ changing with the temperature just as if the blood were being cooled in vitro. With spontaneous ventilation, the $\mathrm{Pa}_{\mathrm{CO}_{2}}$ and $\mathrm{CO}_{2}$ content of the animals at $27^{\circ} \mathrm{C}$ and $\mathrm{MAC} 1$ were not significantly different from the values of these parameters in blood cooled to $27^{\circ} \mathrm{C}$ in vitro. However, since $\mathrm{Pa}_{\mathrm{CO}_{2}}$ tended to be higher and the $\mathrm{CO}_{2}$ content tended to be lower, the $\mathrm{pH}_{\mathrm{a}}$ during hypothermia was significantly lower than in blood cooled in vitro. It is possible that if the low $\mathrm{pH}_{\mathrm{a}}$ had been maintained with ventilation constant, the $\mathrm{PaCO}_{2}$ would have fallen further, since there is a transient elevation of $\mathrm{PaCO}_{2}$ during metabolic acidosis due to freed body stores. It seems that animals breathing spontaneously during hypothermia, under light anaesthesia, respond with ventilation sufficient to produce carbon dioxide elimination equal to metabolic production.

\section{SUMMARY}

The primary effect of hypothermia on the respiratory response to carbon dioxide, studied in five dogs, is shown to be a shift of the $\mathrm{CO}_{2}$ response curve to the left with no significant change in the slope. If one does not take into account the fact that anaesthesia deepens during hypothermia for the same concentration of anaesthetic inhaled, then the slope of the $\mathrm{CO}_{2}$ response curve becomes markedly depressed. This may be the reason for the clinical impression of some observers that hypothermia depresses ventilation. 


\section{RÉSUMÉ}

Nous avons étudié sur cinq chiens l'effet de l'hypothermie sur la réponse respiratoire au dioxyde de carbone. L'étude a montré que l'effet primaire est une déviation vers la gauche de la courbe de la réponse au $\mathrm{CO}_{2}$ sans changement important dans l'allure. Si l'on ne tient pas compte du fait que, au cours de l'hypothermie, l'anesthésie s'approfondit en conservant la même concentration d'agent anesthésique inhalé, alors l'allure de la courbe à la réponse au $\mathrm{CO}_{2}$ est fortement déprimée. Cela pourrait donner une explication de limpression clinique de quelques observateurs qui prétendent que l'hypothermie déprime la ventilation.

\section{REFERENCES}

1. Regan, M. J. \& Eger, E. I., II. Ventilatory Responses to Hypercapnia and Hypoxia at Normothermia and Moderate Hypothermia during Constant-Depth Halothane Anesthesia. Anesthesiology. 27: 624 (1966).

2. Salzano, J. \& Hall, F. G. Effect of Hypothermia on Ventilatory Response to Carbon Dioxide Inhalation and Carbon Dioxide Infusion in Dogs. J. Appl. Physiol. 15: 397 (1960).

3. Cranston, W. I.; Pepper, M. C.; \& Ross, D. N. Carbon Dioxide and Control of Respiration during Hypothermia. J. Physiol. 127: 380 (1955).

4. MERKEL, G. \& EGER, E. I., I. A Comparative Study of Halothane and Halopropane Anesthesia, Including Method for Determining Equipotency. Anesthesiology. 24: 346 (1963).

5. Severinghaus, J. W. Blood-gas Calculator. J. Appl. Physiol. 21 : 1108 (1966).

6. Bellvinle, J. W. \& SEED, J. C. The Effect of Drugs on Respiratory Response to $\mathrm{CO}_{2}$. Anesthesiology. 21: 727 (1960).

7. Eger, E. I., II; Saidman, L.; \& Brandstater, B. Temperature Dependence of Halothane and Cyclopropane Anesthesia in Dogs: Correlation with Some Theories of Anesthetic Action. Anesthesiology. 26: 764 (1965).

8. Korzumi, K.; Brooks, C. McC.; \& UshiYma, J. Hypothermia and Reaction Patterns of the Nervous System. Ann. New York Acad. Sc. 80: 449 (1959).

9. Severunghaus, J. W. Respiration and Hypothermia. Ann. N.Y. Acad. Sc. $80: 385$ (1959). 